\title{
Pain Across the Menstrual Cycle: Considerations of Hydration
}

\author{
Beverly Tan', Michael Philipp², Stephen Hill ${ }^{2}$, Ahmad Munir Che Muhamed ${ }^{3}$ and \\ Toby Mündel ${ }^{1 *}$ \\ ${ }^{1}$ School of Sport, Exercise and Nutrition, Massey University, Palmerston North, New Zealand, ${ }^{2}$ School of Psychology, \\ Massey University, Palmerston North, New Zealand, ${ }^{3}$ Advanced Medical and Dental Institute, Universiti Sains Malaysia, \\ Pulau Pinang, Malaysia
}

OPEN ACCESS

Edited by:

Anna M. D. Watson,

Monash University, Australia

Reviewed by:

Chirstian Wöber,

Medical University of Vienna, Austria Joyce McClendon Evans,

University of Kentucky, United States

${ }^{*}$ Correspondence:

Toby Mündel

t.munde/@massey.ac.nz

Specialty section:

This article was submitted to

Integrative Physiology,

a section of the journal

Frontiers in Physiology

Received: 21 July 2020

Accepted: 16 September 2020

Published: 08 October 2020

Citation:

Tan B, Philipp M, Hill S, Che Muhamed AM and Mündel $T$ (2020) Pain Across the Menstrual

Cycle: Considerations of Hydration.

Front. Physiol. 11:585667.

doi: 10.3389/fphys.2020.585667
Chronic pain - pain that persists for more than 3 months - is a global health problem and is associated with tremendous social and economic cost. Yet, current pain treatments are often ineffective, as pain is complex and influenced by numerous factors. Hypohydration was recently shown to increase ratings of pain in men, but studies in this area are limited $(n=3)$. Moreover, whether hypohydration also affects pain in women has not been examined. In women, changes in the concentrations of reproductive hormones across menstrual phases may affect pain, as well as the regulation of body water. This indicates potential interactions between the menstrual phase and hypohydration on pain, but this hypothesis has yet to be tested. This review examined the literature concerning the effects of the menstrual phase and hypohydration on pain, to explore how these factors may interact to influence pain. Future research investigating the combined effects of hypohydration and menstrual phase on pain is warranted, as the findings could have important implications for the treatment of pain in women, interpretation of previous research and the design of future studies.

Keywords: pain, menstrual cycle, hydration, drinking, women, hormones

\section{INTRODUCTION}

\section{Human Pain: Why Study It?}

Chronic pain - defined as pain that persists for more than 3 months (Treede et al., 2015), is a major health issue with a high and increasing prevalence locally and globally. In New Zealand, $21 \%$ of adults reported experiencing chronic pain in 2016, an increase of almost 4 from $17 \%$ in 2007 (Ministry of Health, 2016). A survey conducted in the United States estimated that 17\% of the population (39 million adults) suffer from chronic pain (Nahin, 2015), while a recent metaanalysis reported a $43 \%$ (28 million adults) prevalence of chronic pain in the United Kingdom (Fayaz et al., 2016). The prevalence of chronic pain is expected to continue to rise, especially with an aging population. Apart from its debilitating impact on numerous aspects of the lives of the affected individuals and their families (Turk et al., 2011), chronic pain is also associated with tremendous direct and indirect economic costs. A report estimated the total cost of arthritis in New Zealand in 2010 to be $\$ 3.2$ billion (1.7\% of GDP), with almost half of this amount being attributed to productivity losses alone (Access Economics, 2010). The annual cost of pain in the United States in 2008 was reported to be between $\$ 560$ and $\$ 635$ billion dollars, which 
was more than that for heart disease, cancer, and diabetes (Gaskin and Richard, 2012).

\section{Human Pain: How to Study It and on Whom?}

Pain is a highly subjective and individual experience, with an abundance of physical, biological, and psychosocial factors that independently and interactively influence an individual's experience of pain (Gatchel et al., 2007; Fillingim, 2017a). Moreover, chronic pain often does not involve actual tissue damage (Jacobs, 2013). The abstract nature of pain presents major challenges to the treatment and management of pain. Although a broad range of pain treatment options are available, they are often very expensive and only minimally effective in eliminating pain and improving quality of life (Martin et al., 2008; Turk et al., 2011). In fact, the average success rate of pain treatments was reported to be only "roughly $30 \%$ in about half of treated patients" (Turk et al., 2011). Knowledge and understanding of the underlying mechanisms and factors that contribute to pain is fundamental to the development of more effective pain treatment and management strategies.

Research on pain is typically conducted by inducing acute pain using various experimental modalities in healthy, pain-free individuals. Although recruiting patients with chronic pain as participants would enhance ecological validity of these studies, and is often the target population of interventions etc., this is often difficult to do due to the associated logistical and ethical cost. Acute pain is characterized as being temporary, caused by a specific stimulus and acts as a warning signal (Grichnik and Ferrante, 1991; Świeboda et al., 2013). A wide range of pain stimuli have been used in studies on experimental pain. The more commonly used pain modalities are the cold pressor task, muscle ischemia, mechanical pressure, noxious thermal pain (heat and cold) and electrical stimulation. The type of pain evoked by each of these stimuli differ in a number of characteristics, such as the sensations they produce, pain mechanisms they activate, and more importantly, their resemblance to clinical pain (Rainville et al., 1992; Fillingim and Ness, 2000). Of these pain stimuli, the cold pressor task and muscle ischemia are thought to be the most clinically relevant, as the deep and aching pain produced by both of these stimuli may better replicate the pain experienced by patients with chronic pain (Moore et al., 1979; Rainville et al., 1992; Iacovides et al., 2015a). The responses to these pain stimuli can be assessed using various measures: pain threshold (least amount of a stimulus that elicits feelings of pain), pain tolerance (maximum amount of a painful stimulus that an individual can or is willing to experience) and/or subjective ratings of pain intensity and pain unpleasantness (Edens and Gil, 1995; Hastie et al., 2005; IASP, 2017). Throughout this review, pain sensitivity will refer to the outcome of one, or a combination, of these measures.

To date, most of the studies on acute experimental pain have been performed exclusively in male participants, with only a handful performed in women. For instance, among non-human animal studies on pain, $79 \%$ of studies that were published from 1996 to 2005 were performed solely in male animals, compared to a mere $8 \%$ in female animals (Mogil and Chanda, 2005).
In the human literature, a similar bias toward males has been observed across many disciplines, including behavioral research (Beery and Zucker, 2011). Yet, there are clear sex differences in both chronic and acute experimental pain (Unruh, 1996; Berkley, 1997; Riley et al., 1998; Fillingim et al., 2009). In women specifically, the female reproductive hormones and their fluctuation across different menstrual phases can influence pain. Furthermore, these hormones can also affect hydration status - a variable that has recently been implicated as a contributing factor to pain in men, although this has not been investigated in women. Given that women make up half of the global population, it is important to focus specific research on pain in this population. Increased understanding of pain in women could have important implications for the treatment and management of pain, which could ultimately help alleviate the detrimental economic and social consequences of pain.

Several reviews on pain and the menstrual phase have been published (Riley et al., 1999; Sherman and LeResche, 2006; Martin, 2009; Hassan et al., 2014; Iacovides et al., 2015a). However, none of these reviews have addressed the topic with a consideration of hydration status. Therefore, the purposes of this review are to: (i) summarize the existing literature on pain in women, specifically as it relates to the menstrual phase and hydration status, and (ii) make recommendations for future research. A search of the published literature was performed through July 2020 using the PubMed database and Google Scholar search engine, whilst second- and third-order reference lists were checked manually for relevant articles.

\section{PAIN IN WOMEN}

Sex differences in pain have been extensively studied and research in this area has dominated the pain literature for years (Fillingim et al., 2009). Several comprehensive reviews and meta-analyses on the topic have since been published, which readers are referred to (e.g., Riley et al., 1998; Fillingim et al., 2009; Mogil, 2012; Hashmi and Davis, 2014; Fillingim, 2017b). Overall, there appears to be agreement that women are more sensitive to acute experimental pain than men and many specific chronic pain conditions are also more prevalent among women compared to men (Fillingim et al., 2009; Mogil, 2012). Sex differences in pain modulation pathways, such as opioid analgesia and conditioned pain modulation, have also been reported (Fillingim and Ness, 2000; Paller et al., 2009; Niesters et al., 2010; Popescu et al., 2010; Pisanu et al., 2019). As such, these findings underscore the importance of studying pain in women specifically as it can have implications for the treatment of their pain.

\section{Overview of Menstrual Cycle Physiology}

Plasma concentrations of the main ovarian hormones - estrogen, progesterone, luteinizing hormone (LH) and follicle-stimulating hormone $(\mathrm{FSH})$ - change cyclically during the menstrual cycle. The menstrual cycle, which lasts for an average of 28 days, can be broadly divided into the follicular and luteal phases. The follicular phase begins with the first day of menses and lasts until ovulation ( $\sim$ day 14 ). During this phase, estrogen 
concentrations initially remain low and stable while menses occurs, increase steadily after cessation of menses, then rise sharply and peak during the last few days of the follicular phase. Progesterone concentrations, on the other hand, remain low throughout the follicular phase. Following the estrogen spike, a mid-cycle surge in LH occurs, resulting in ovulation and the start of the luteal phase. The luteal phase is generally characterized by a rise in progesterone concentrations to its highest point and a concomitant rise in estrogen to moderate concentrations. Toward the end of the luteal phase, both progesterone and estrogen concentrations fall rapidly, resulting in the onset of menses and the start of a new cycle.

Besides these hormonal variations, women also tend to experience fluctuations in several physical and emotional symptoms such as bloatedness, fatigue, irritability, and anxiety over the course of the menstrual cycle (Pfleeger et al., 1997; Alonso et al., 2004). Of importance to this review, recent experimental and clinical data have also shown changes in chronic and acute experimental pain across the menstrual cycle (Martin, 2009; Hassan et al., 2014).

\section{Acute Experimental Pain and the Menstrual Phase}

An early meta-analysis by Riley et al. (1999) and a subsequent review by Martin (2009) both concluded that there are modest effects of the menstrual cycle phase on experimental pain sensitivity in healthy women, although the direction of effects reported by both groups of authors are contradictory. Riley et al. (1999) found lower pain sensitivity in the follicular compared to luteal phase, whereas Martin (2009) concluded that pain sensitivity was higher in the follicular phase. In contrast, Sherman and LeResche (2006) reported that the available findings are largely equivocal. Similarly, a recent review of 42 studies by Iacovides et al. (2015a) concluded that the current body of research does not paint a definitive picture on whether the menstrual cycle phase affects experimental pain sensitivity. The conflicting findings are largely due to the numerous methodological variations across studies, such as differences in the experimental pain stimuli used and definition of menstrual phases. Moreover, many studies also did not confirm that participants had ovulated or measure plasma concentrations of estrogen and progesterone to verify menstrual phase, which could subsequently affect the interpretation of study results. These various methodological differences and limitations have been comprehensively reviewed by Sherman and LeResche (2006), which readers are referred to. Interestingly, a slightly greater proportion $(64 \%)$ of the studies reviewed by Iacovides et al. (2015a) found variations in experimental pain sensitivity across the menstrual cycle. However, the authors noted that the more well-controlled studies mostly did not find any effect of the menstrual cycle phase on pain sensitivity, although these studies were not without some of the methodological limitations as pointed out by Sherman and LeResche (2006). To the best of our knowledge, nine recent studies have been published since the time of the last review in 2015 (Bartley et al., 2015; Iacovides et al., 2015b; Cankar et al., 2016; Palit et al., 2016; Alves et al.,
2017; Nayak et al., 2017; Jasrotia et al., 2018; Payne et al., 2019; Pogatzki-Zahn et al., 2019); these findings also appear to be inconsistent. There is a roughly equal number of studies that observed variations in pain sensitivity across the menstrual cycle (5/9 studies) and those that did not (4/9 studies).

A small number of studies have investigated whether the menstrual cycle phase affects experimental pain sensitivity in women with chronic pain conditions. Like the research in healthy women, the findings of these studies are also largely inconsistent. Three studies found variations in experimental pain sensitivity across the menstrual cycle (Isselée et al., 2002; Sherman et al., 2005; Teepker et al., 2011), while four studies did not observe any variability (Alonso et al., 2004; Okifuji and Turk, 2006; Vignolo et al., 2008; Balter et al., 2013).

\section{Experimental Pain Modulation and the Menstrual Phase}

It has been suggested that some of the observed effects of the menstrual phase on experimental pain sensitivity could be related to endogenous pain modulation mechanisms, which consist of pain inhibitory and facilitatory pathways. Pain modulation in humans can be studied experimentally using various methods, with the Conditioned Pain Modulation (CPM) paradigm being the most widely used (Yarnitsky et al., 2010; Lewis et al., 2012; Kennedy et al., 2016). The CPM, which assesses the pain inhibition pathway, involves applying an experimental pain stimulus in one part of the body to dampen the pain produced by another pain stimulus at a different body part (Damien et al., 2018).

To the best of our knowledge, there are nine studies that have examined pain modulation across the menstrual cycle in healthy pain-free women. Seven of these studies assessed pain inhibition using the CPM paradigm (Tousignant-Laflamme and Marchand, 2009; Rezaii and Ernberg, 2010; Bartley and Rhudy, 2012; Rezaii et al., 2012; Wilson et al., 2013; Teepker et al., 2014; Palit et al., 2016). The other two studies used an emotional picture-viewing paradigm that assesses both pain inhibition and pain facilitation. In this method, a series of pictures intended to evoke negative and positive emotions were displayed to participants in order to enhance or reduce, respectively, the perceived intensity of a noxious stimulus (Rhudy and Bartley, 2010; Rhudy et al., 2013). A majority of the CPM studies (5/7 studies) did not observe changes in the magnitude of pain inhibition across the menstrual cycle, while both studies on emotional pain modulation also did not report any menstrual cycle phase effects on emotional pain inhibition or facilitation.

In the only study that investigated pain modulation across the menstrual cycle in women with a chronic pain condition (migraine), no effect of the menstrual cycle phase on CPM inhibition was observed (Teepker et al., 2014).

\section{Chronic Pain Severity and the Menstrual Phase}

In contrast to the uncertainty regarding the menstrual cycle effects on experimental pain sensitivity, studies examining the relationship between the menstrual cycle and chronic pain 
have produced more consistent results. There are currently two reviews on this topic that have been published. The authors of both reviews found robust evidence indicating that there is menstrual cycle-related variability in the severity of pain symptoms in women with various chronic pain conditions (i.e., migraine, temporomandibular pain disorder, fibromyalgia, rheumatoid arthritis, and irritable bowel syndrome). Moreover, the majority of data appear to show a worsening of self-reported pain severity during the early-follicular and/or late-luteal phase, when plasma estrogen concentrations are low (Martin, 2009; Hassan et al., 2014). However, much of the chronic pain research is also confounded by the various methodological problems and disparities across studies that are present in the experimental pain literature.

\section{Summary of Pain in Women}

Despite the relatively large body of research on the menstrual cycle and experimental pain sensitivity, there is currently no agreement among researchers on whether the menstrual cycle does, or does not, affect experimental pain sensitivity, in both healthy women and those with chronic pain conditions. Regarding pain modulation and the menstrual cycle, the limited number of studies in this area mostly did not observe any menstrual cycle effects on CPM inhibition or emotional pain modulation. In contrast, the severity of pain symptoms for many chronic pain conditions has consistently been shown to vary across the menstrual cycle. Although incompletely understood, the potential mechanisms underlying the variation in pain across menstrual phases could be due to effects of the female reproductive hormones on various pain pathways in the central and peripheral nervous systems, responses to stress and inflammation, and neurotransmitters such as serotonin and $\alpha$-aminobutyric acid (GABA) (Marcus, 1995; Martin, 2009). However, a discussion on the mechanisms is beyond the scope of this review and interested readers are directed to excellent reviews on this topic (Fillingim and Maixner, 1995; Aloisi and Bonifazi, 2006; Amandusson and Blomqvist, 2013).

The overall ambiguity in this area of research is mostly due to the various methodological inconsistencies and limitations across many of the studies. While a handful of studies have sought to address some of these problems, such as measuring plasma reproductive hormone concentrations and confirming ovulation, there is a paucity of such better-controlled studies. Moreover, none of the previous studies assessed the hydration status of participants, which could be a possible confound.

\section{HYDRATION, MENSTRUAL PHASE, AND PAIN}

Euhydration is a state of normal body water content, whereas hypohydration refers to the state of reduced body water content that exceeds the normal daily fluctuations ( $>2 \%$ body mass loss) (Greenleaf, 1992; American College of Sports Medicine et al., 2007). While there is some variability across studies and individuals, the commonly used biochemical thresholds for defining hypohydration are: serum osmolality
$\left(\mathrm{S}_{\text {Osm }}\right)>290 \mathrm{mOsm} \mathrm{kg}^{-1}$, urine specific gravity $($ USG) $>1.020$ and/or urine osmolality $\left(\mathrm{U}_{\mathrm{Osm}}\right)>700 \mathrm{mOsm} \mathrm{kg}{ }^{-1}$ (Cheuvront and Sawka, 2005; American College of Sports Medicine et al., 2007; Armstrong et al., 2010, 2012b). Dehydration, on the other hand, refers to the process of fluid loss that results in hypohydration (Akerman et al., 2016; Nuccio et al., 2017).

Hypohydration occurs when body fluid losses exceed fluid intake. Excessive fluid losses incurred through sweating (e.g., prolonged exercise, strenuous work, environmental heat exposure) is perhaps the most common way individuals become hypohydrated. This is especially prevalent among athletes, where around $75 \%$ of them are already hypohydrated upon arrival for training sessions (Volpe et al., 2009; Arnaoutis et al., 2015; Magal et al., 2015). However, inadequate fluid intake during normal daily activities can also lead to hypohydration. Therefore, hypohydration is also a problem among the general public beyond athletes (Manz and Wentz, 2005; Chang et al., 2016).

\section{Hypohydration and Pain}

Hypohydration has been shown to negatively impact cognitive function, mood state, and fatigue in women (Szinnai et al., 2005; Armstrong et al., 2012a; Pross et al., 2013). These factors, in turn, can contribute to pain (Willoughby et al., 2002), therefore indicating a possible relationship between hypohydration and pain. Indeed, recent research indicates that hypohydration can increase pain. Mild hypohydration of as little as a $1 \%$ body mass loss, induced by a combination of fasting and exercise, invoked greater activation in pain-related regions of the brain during an experimental pain task in men (Ogino et al., 2014). Experimental pain sensitivity was also higher when participants were hypohydrated, compared to when they were euhydrated. Similar observations were made in a later study, where a group of men dehydrated by restricting fluid intake for $24 \mathrm{~h}$ (Bear et al., 2016). Mild hypohydration ( $1 \%$ body mass loss) was found to increase experimental pain sensitivity relative to the euhydration condition. However, both studies were exclusively performed in men and it is not known whether hypohydration can also contribute to pain in women. In the only study that included female participants, Moyen et al. (2015) conducted a field study on 103 male and 16 female cyclists who were taking part in an ultraendurance race. Cyclists who were hypohydrated before and during the race reported more intense pain in their leg muscles compared to the euhydrated cyclists. The authors also reported examining possible differences in the pain ratings between the male and female cyclists and did not find sex differences, indicating that hypohydration may also increase pain in women. However, the effect of hypohydration on pain in women has not been formally investigated. This is important as the menstrual phase is associated with variation in body fluid regulation, in addition to their potential impacts on pain as discussed previously.

\section{Hydration and the Menstrual Phase}

One of the more prominent impacts of the menstrual phase on hydration is the osmotic control of arginine vasopressin 
(AVP) and thirst sensation (Spruce et al., 1985; Vokes et al., 1988; Stachenfeld, 2008). AVP, also known as anti-diuretic hormone, is one of the primary hormones involved in body fluid regulation and its main effect in this context is to increase free water retention in the kidneys (Baylis, 1987). Meanwhile, thirst sensation is the key driver of fluid intake (McKinley and Johnson, 2004). Both AVP and thirst are primarily stimulated by an increase in plasma osmolality (a biomarker of hydration status), such as during dehydration (Baylis, 1987; McKinley and Johnson, 2004).

The luteal phase has been associated with a lowering of the osmotic thresholds at which AVP is released and thirst sensation increases (Spruce et al., 1985; Vokes et al., 1988; Stachenfeld et al., 1999b, 2001) - effects that are primarily attributed to estrogen (Calzone et al., 2001; Stachenfeld and Keefe, 2002). In other words, less of an osmotic stimulus is required to activate the AVP and thirst responses (and their respective effects on increasing renal water retention and fluid intake) during the luteal phase (Giersch et al., 2019). There could also be increased sodium (thus water) retention in the luteal phase, by way of the progesterone-related increased plasma aldosterone concentrations during this phase (Souza et al., 1989; Stachenfeld et al., 1999a, 2001). Moreover, other studies have also observed an increase in body water content measured by bioelectrical impedance analysis during the luteal versus follicular phase (Bunt et al., 1989; Mitchell et al., 1993; Tomazo-Ravnik and Jakopiè, 2006; Fruzzetti et al., 2007; Stachoń, 2016). Therefore, these findings indicate that women may be more protected against dehydration in the luteal compared to follicular phase. Yet, a decreased plasma volume - the fluid component of the blood that is most affected by changes in hydration status - during the luteal phase is also commonly reported (Stephenson and Kolka, 1988; Stachenfeld et al., 1999b, 2001). This is thought to be caused by the preferential movement of fluid from the intravascular space into the interstitium (Øian et al., 1987). Nevertheless, these findings demonstrate that there are differences in body fluid regulation between menstrual phases, which could subsequently affect hydration status.

More importantly, research indicates that hypohydration is a common occurrence among women. A study by Malisova et al. (2016) showed that approximately $20 \%$ of the women in Europe met the criteria for hypohydration $\left(\mathrm{U}_{\mathrm{Osm}}>810 \mathrm{mOsm} \mathrm{kg}{ }^{-1}\right)$. In the United States, data from the third National Health and Nutrition Examination Survey (NHANES III) on nearly 8,000 women showed half of the women to be hypohydrated (plasma tonicity $>295 \mathrm{mmom} \mathrm{L}^{-1}$ ) (Stookey, 2005). Furthermore, hypohydration appears to be especially prevalent among the older population. Approximately $30 \%$ of older women (aged 50 years and above) were found to be markedly hypohydrated (plasma tonicity $\geq 300 \mathrm{mmom} \mathrm{L}^{-1}$ ), compared to $\sim 10 \%$ in the younger women (Stookey, 2005). Similarly, Hooper et al. (2015) found that $40 \%$ of elderly women living in residential homes met the criteria for hypohydration $\left(\mathrm{S}_{\mathrm{Osm}}>295 \mathrm{mOsm} \mathrm{kg}{ }^{-1}\right)$, while another study also identified $40 \%$ of elderly women to be hypohydrated upon admission to hospital (serum sodium $>150 \mathrm{mg} \mathrm{dL}^{-1}$ and/or ratio of blood urea nitrogen to creatine $>25$ ) (Lavizzo-Mourey et al., 1988).

\section{Implications of Hydration for Pain in Women}

The findings of a hyperalgesic effect of hypohydration in men, and of the potential menstrual phase effects on pain and hydration, have several potential implications for the study and treatment of pain in women. Firstly, hydration status could have confounded previous research on the menstrual phase and pain and contributed to the conflicting findings in the literature. Differences in hydration status between menstrual phases could either exaggerate or mask the menstrual phase effects on pain, resulting in erroneous conclusions about the associations between menstrual phase and pain. However, hydration status was not measured in previous studies on this topic. It may, therefore, be necessary for future research to measure and control for hydration status in order to clarify some of the confusion regarding the effects of the menstrual phase on pain. Secondly, since both the menstrual phase and hypohydration can independently affect pain, they could have interactive effects on pain when combined. In this instance, hypohydration could have a more pronounced hyperalgesic effect in one menstrual phase compared to another. However, this hypothesis has not been investigated. Lastly, hypohydration could reduce the efficacy of pain treatments. For example, Parker et al. (2012) assessed the effect of hypohydration (36 h of fluid restriction) on the outcomes of an osteopathic manipulative treatment program in 8 women and 11 men with chronic low back pain. Greater improvements in treatment outcomes were observed when participants attended the treatment sessions in a euhydrated versus hypohydrated state. Therefore, it may be important for clinicians and practitioners to assess the hydration status of pain patients to maximize the efficacy of the treatments.

\section{CONCLUSION}

There is currently no definitive conclusion regarding the effects of the menstrual phase on pain. Apart from the methodological limitations and differences (menstrual phase verification, type of experimental pain stimulus etc.) across studies that could explain the conflicting findings, hydration status could also have contributed to the equivocal results in the literature. Hypohydration was shown to increase pain in men, but whether this occurs in women has not been examined. Further, the menstrual phase may influence hydration status. This indicates that hydration status could be a confounding factor in the research on pain in women. Further, hydration status could also influence the pain outcomes, either independently or interactively with the menstrual phase.

Future research should focus on investigating the effects of hypohydration on pain in women across different menstrual phases, including the potential mechanisms that could explain any observed effects. The findings from this research have several important implications: it could (i) help us better understand and interpret previous research on pain in women, particularly as it relates to the menstrual phase, (ii) assist in 
designing more high-quality research in this area, and (iii) aid in developing strategies to improve the treatment and management of pain in women. The importance and necessity of this research is further underscored by the common occurrence of hypohydration among women. Lastly, while this review focused on premenopausal, normally cycling women, it is also important to address these questions in oral contraceptive users and postmenopausal women due to their different hormonal profiles that could affect their pain responses and/or hydration status (Stachenfeld, 2008; Fillingim et al., 2009; Iacovides et al., 2015a).

\section{REFERENCES}

Access Economics (2010). The Economic Cost of Arthritis in New Zealand in 2010. Available online at: https://www.arthritis.org.nz/pdfs/economic-cost-ofarthritis-in-new-zealand-final-print.pdf

Akerman, A. P., Tipton, M., Minson, C. T., and Cotter, J. D. (2016). Heat stress and dehydration in adapting for performance: good, bad, both, or neither? Temperature 3, 412-436. doi: 10.1080/23328940.2016.1216255

Aloisi, A. M., and Bonifazi, M. (2006). Sex hormones, central nervous system and pain. Horm. Behav. 50, 1-7. doi: 10.1016/j.yhbeh.2005.12.002

Alonso, C., Loevinger, B. L., Muller, D., and Coe, C. L. (2004). Menstrual cycle influences on pain and emotion in women with fibromyalgia. J. Psychosom. Res. 57, 451-458. doi: 10.1016/j.jpsychores.2004.05.003

Alves, B., Ibuki, F., Gonçalves, A. S., Teixeira, M. J., and De Siqueira, S. R. D. T. (2017). Influence of sexual hormones on neural orofacial perception. Pain Med. 18, 1549-1556. doi: 10.1093/pm/pnw272

Amandusson, A., and Blomqvist, A. (2013). Estrogenic influences in pain processing. Front. Neuroendocrinol. 34, 329-349. doi: 10.1016/j.yfrne.2013.06. 001

American College of Sports Medicine, Sawka, M. N., Burke, L. M., Eichner, E. R., Maughan, R. J., Montain, S. J., et al. (2007). American college of sports medicine position stand. Exercise and fluid replacement. Med. Sci. Sports Exerc. 39, 377-390. doi: 10.1249/mss.0b013e31802ca597

Armstrong, L. E., Ganio, M. S., Casa, D. J., Lee, E. C., McDermott, B. P., Klau, J. F., et al. (2012a). Mild dehydration affects mood in healthy young women. J. Nutr. 142, 382-388. doi: 10.3945/jn.111.142000

Armstrong, L. E., Johnson, E. C., Munoz, C. X., Swokla, B., Le Bellego, L., Jimenez, L., et al. (2012b). Hydration biomarkers and dietary fluid consumption of women. J. Acad. Nutr. Diet. 112, 1056-1061. doi: 10.1016/j.jand.2012.03.036

Armstrong, L. E., Pumerantz, A. C., Fiala, K. A., Roti, M. W., Kavouras, S. A., Casa, D. J., et al. (2010). Human hydration indices: acute and longitudinal reference values. Int. J. Sport Nutr. Exerc. Metab. 20, 145-153. doi: 10.1123/ijsnem.20. 2.145

Arnaoutis, G., Kavouras, S. A., Angelopoulou, A., Skoulariki, C., Bismpikou, S., Mourtakos, S., et al. (2015). Fluid balance during training in elite young athletes of different sports. J. Strength Cond. Res. 29, 3447-3452. doi: 10.1519/JSC. 0000000000000400

Balter, J. E., Molner, J. L., Kohrt, W. M., and Maluf, K. S. (2013). Mechanical pain sensitivity and the severity of chronic neck pain and disability are not modulated across the menstrual cycle. J. Pain 14, 1450-1459. doi: 10.1016/j. jpain.2013.07.008

Bartley, E. J., Palit, S., Kuhn, B. L., Kerr, K. L., Terry, E. L., DelVentura, J. L., et al. (2015). Nociceptive processing in women with premenstrual dysphoric disorder (PMDD): the role of menstrual phase and sex hormones. Clin. J. Pain 31, 304-314. doi: 10.1097/AJP.0000000000000112

Bartley, E. J., and Rhudy, J. L. (2012). Endogenous inhibition of the nociceptive flexion reflex (NFR) and pain ratings during the menstrual cycle in healthy women. Ann. Behav. Med. 43, 343-351. doi: 10.1007/s12160-012-9345-x

Baylis, P. H. (1987). Osmoregulation and control of vasopressin secretion in healthy humans. Am. J. Physiol. Regul. Integr. Comp. Physiol. 253, R671-R678. doi: 10.1152/ajpregu.1987.253.5.R671

Bear, T., Philipp, M., Hill, S., and Mündel, T. (2016). A preliminary study on how hypohydration affects pain perception. Psychophysiology 53, 605-610. doi: 10.1111/psyp. 12610

\section{DATA AVAILABILITY STATEMENT}

The original contributions presented in the study are included in the article, further inquiries can be directed to the corresponding author.

\section{AUTHOR CONTRIBUTIONS}

All authors listed have made a substantial, direct and intellectual contribution to the work, and approved it for publication.

Beery, A. K., and Zucker, I. (2011). Sex bias in neuroscience and biomedical research. Neurosci. Biobehav. Rev. 35, 565-572. doi: 10.1016/j.neubiorev.2010. 07.002

Berkley, K. J. (1997). Sex differences in pain. Behav. Brain Sci. 20, 371-380; discussion 435-513. doi: 10.1017/s0140525x97221485

Bunt, J. C., Lohman, T. G., and Boileau, R. A. (1989). Impact of total body water fluctuations on estimation of body fat from body density. Med. Sci. Sports Exerc. 21, 96-100.

Calzone, W. L., Silva, C., Keefe, D. L., and Stachenfeld, N. S. (2001). Progesterone does not alter osmotic regulation of AVP. Am. J. Physiol. Regul. Integr. Comp. Physiol. 281, R2011-R2020.

Cankar, K., Music, M., and Finderle, Z. (2016). Cutaneous microvascular response during local cold exposure - the effect of female sex hormones and cold perception. Microvasc. Res. 108, 34-40. doi: 10.1016/j.mvr.2016.07.006

Chang, T., Ravi, N., Plegue, M. A., Sonneville, K. R., and Davis, M. M. (2016). Inadequate hydration, BMI, and obesity among US adults: NHANES 20092012. Ann. Fam. Med. 14, 320-324. doi: 10.1370/afm.1951

Cheuvront, S. N., and Sawka, M. N. (2005). Hydration assessment of athletes. Sports Sci. Exch. 18, 1-6.

Damien, J., Colloca, L., Bellei-Rodriguez, C. -É., and Marchand, S. (2018). Pain modulation: from conditioned pain modulation to placebo and nocebo effects in experimental and clinical pain. Int. Rev. Neurobiol. 139, 255-296. doi: 10. 1016/bs.irn.2018.07.024

Edens, J. L., and Gil, K. M. (1995). Experimental induction of pain: utility in the study of clinical pain. Behav. Ther. 26, 197-216.

Fayaz, A., Croft, P., Langford, R. M., Donaldson, L. J., and Jones, G. T. (2016). Prevalence of chronic pain in the UK: a systematic review and meta-analysis of population studies. BMJ Open 6:e010364.

Fillingim, R. B. (2017a). Individual differences in pain: understanding the mosaic that makes pain personal. Pain 158(Suppl. 1), S11-S18. doi: 10.1097/j.pain. 0000000000000775

Fillingim, R. B. (2017b). Principles of Gender-Specific Medicine, 3rd Edn, ed. M. J. Legato (San Diego, CA: Academic Press), 481-496.

Fillingim, R. B., King, C. D., Ribeiro-Dasilva, M. C., Rahim-Williams, B., and Riley, J. L. III (2009). Sex, gender, and pain: a review of recent clinical and experimental findings. J. Pain 10, 447-485. doi: 10.1016/j.jpain.2008.12.001

Fillingim, R. B., and Maixner, W. (1995). Gender differences in the responses to noxious stimuli. Pain Forum 4, 209-221. doi: 10.1016/S1082-3174(11)80022-X

Fillingim, R. B., and Ness, T. J. (2000). Sex-related hormonal influences on pain and analgesic responses. Neurosci. Biobehav. Rev. 24, 485-501.

Fruzzetti, F., Lazzarini, V., Ricci, C., Quirici, B., Gambacciani, M., Paoletti, A. M., et al. (2007). Effect of an oral contraceptive containing 30 microg ethinylestradiol plus $3 \mathrm{mg}$ drospirenone on body composition of young women affected by premenstrual syndrome with symptoms of water retention. Contraception 76, 190-194. doi: 10.1016/j.contraception.2007.05.080

Gaskin, D. J., and Richard, P. (2012). The economic costs of pain in the United States. J. Pain 13, 715-724. doi: 10.1016/j.jpain.2012.03.009

Gatchel, R. J., Peng, Y. B., Peters, M. L., Fuchs, P. N., and Turk, D. C. (2007). The biopsychosocial approach to chronic pain: scientific advances and future directions. Psychol. Bull. 133, 581-624. doi: 10.1037/0033-2909.133. 4.581

Giersch, G. E. W., Charkoudian, N., Stearns, R. L., and Casa, D. J. (2019). Fluid balance and hydration considerations for women: review and future directions. Sports Med. 50, 253-261. doi: 10.1007/s40279-40019-01206-40276 
Greenleaf, J. E. (1992). Problem: thirst, drinking behavior, and involuntary dehydration. Med. Sci. Sports Exerc. 24, 645-656.

Grichnik, K. P., and Ferrante, F. M. (1991). The difference between acute and chronic pain. Mt. Sinai J. Med. 58, 217-220.

Hashmi, J. A., and Davis, K. D. (2014). Deconstructing sex differences in pain sensitivity. Pain 155, 10-13. doi: 10.1016/j.pain.2013.07.039

Hassan, S., Muere, A., and Einstein, G. (2014). Ovarian hormones and chronic pain: a comprehensive review. Pain 155, 2448-2460. doi: 10.1016/j.pain.2014.08.027

Hastie, B. A., Riley, J. L. III, Robinson, M. E., Glover, T., Campbell, C. M., Staud, R., et al. (2005). Cluster analysis of multiple experimental pain modalities. Pain $116,227-237$

Hooper, L., Bunn, D. K., Downing, A., Jimoh, F. O., Groves, J., Free, C., et al. (2015). Which frail older people are dehydrated? The UK DRIE Study. J. Gerontol. A Biol. Sci. Med. Sci. 71, 1341-1347. doi: 10.1093/gerona/glv205

Iacovides, S., Avidon, I., and Baker, F. C. (2015a). Does pain vary across the menstrual cycle? A review. Eur. J. Pain 19, 1389-1405. doi: 10.1002/ejp.714

Iacovides, S., Avidon, I., and Baker, F. C. (2015b). Women with dysmenorrhoea are hypersensitive to experimentally induced forearm ischaemia during painful menstruation and during the pain-free follicular phase. Eur. J. Pain 19, 797-804. doi: $10.1002 /$ ejp.604

IASP (2017). IASP Terminology. Washington, DC: IASP.

Isselée, H., De Laat, A., De Mot, B., and Lysens, R. (2002). Pressure-pain threshold variation in temporomandibular disorder myalgia over the course of the menstrual cycle. J. Orofac. Pain 16, 105-117.

Jacobs, M. S. (2013). Psychological factors influencing chronic pain and the impact of litigation. Curr. Phys. Med. Rehabil. Rep. 1, 135-141.

Jasrotia, R. B., Kanchan, A., Harsoda, J. M., Saini, R., and Agarwal, M. (2018). Pain sensitivity and cardiovascular reactivity to the experimental induced cold pressor pain during different phases of menstrual cycle in young Indian females. Natl. J. Physiol. Pharm. Pharmacol. 8, 273-277. doi: 10.5455/njppp.2018.8. 1248725122017

Kennedy, D. L., Kemp, H. I., Ridout, D., Yarnitsky, D., and Rice, A. S. (2016). Reliability of conditioned pain modulation: a systematic review. Pain 157, 2410-2419.

Lavizzo-Mourey, R., Johnson, J., and Stolley, P. (1988). Risk factors for dehydration among elderly nursing home residents. J. Am. Geriatr. Soc. 36, 213-218. doi: 10.1111/j.1532-5415.1988.tb01803.x

Lewis, G. N., Rice, D. A., and McNair, P. J. (2012). Conditioned pain modulation in populations with chronic pain: a systematic review and meta-analysis. J. Pain 13, 936-944. doi: 10.1016/j.jpain.2012.07.005

Magal, M., Cain, R. J., Long, J. C., and Thomas, K. S. (2015). Pre-practice hydration status and the effects of hydration regimen on collegiate division III male athletes. J. Sports Sci. Med. 14, 23-28.

Malisova, O., Athanasatou, A., Pepa, A., Husemann, M., Domnik, K., Braun, H., et al. (2016). Water intake and hydration indices in healthy European adults: the European hydration research study (EHRS). Nutrients 8:204. doi: 10.3390/ nu8040204

Manz, F., and Wentz, A. (2005). Hydration status in the United States and Germany. Nutr. Rev. 63(Suppl._1), S55-S62. doi: 10.1111/j.1753-4887.2005. tb00154.x

Marcus, D. A. (1995). Interrelationships of neurochemicals, estrogen, and recurring headache. Pain 62, 129-139. doi: 10.1016/0304-3959(95)00052-t

Martin, B. I., Deyo, R. A., Mirza, S. K., Turner, J. A., Comstock, B. A., Hollingworth, W., et al. (2008). Expenditures and health status among adults with back and neck problems. JAMA 299, 656-664. doi: 10.1001/jama.299.6.656

Martin, V. T. (2009). Ovarian hormones and pain response: a review of clinical and basic science studies. Gend. Med. 6(Suppl. 2), 168-192. doi: 10.1016/j.genm. 2009.03.006

McKinley, M. J., and Johnson, A. K. (2004). The physiological regulation of thirst and fluid intake. Physiology 19, 1-6. doi: 10.1152/nips.01470.2003

Ministry of Health (2016). New Zealand Health Survey 2015/16. Available online at: https://www.health.govt.nz/system/files/documents/publications/annualupdate-key-results-2015-16-nzhs-dec16-v2.pdf

Mitchell, C. O., Rose, J., Familoni, B., Winters, S., and Ling, F. (1993). The use of multifrequency bioelectrical impedance analysis to estimate fluid volume changes as a function of the menstrual cycle. Basic Life Sci. 60, 189-191. doi: 10.1007/978-1-4899-1268-8_43
Mogil, J. S. (2012). Sex differences in pain and pain inhibition: multiple explanations of a controversial phenomenon. Nat. Rev. Neurosci. 13, 859-866. doi: $10.1038 / \mathrm{nrn} 3360$

Mogil, J. S., and Chanda, M. L. (2005). The case for the inclusion of female subjects in basic science studies of pain. Pain 117, 1-5. doi: 10.1016/j.pain.2005.06.020

Moore, P. A., Duncan, G. H., Scott, D. S., Gregg, J. M., and Ghia, J. N. (1979). The submaximal effort tourniquet test: its use in evaluating experimental and chronic pain. Pain 6, 375-382.

Moyen, N. E., Ganio, M. S., Wiersma, L. D., Kavouras, S. A., Gray, M., McDermott, B. P., et al. (2015). Hydration status affects mood state and pain sensation during ultra-endurance cycling. J. Sports Sci. 33, 1962-1969. doi: 10.1080/02640414. 2015.1021275

Nahin, R. L. (2015). Estimates of pain prevalence and severity in adults: United States, 2012. J. Pain 16, 769-780. doi: 10.1016/j.jpain.2015.05.002

Nayak, V. K. R., Chikkanna, S., Devi, M. S., and Vidya, J. (2017). Comparative study of response to experimental cold pain in dysmenorrheic and nondysmenorrheic women. Natl. J. Physiol. Pharm. Pharmacol. 7, 416-419. doi: 10.5455/njppp. 2017.7.1132721122016

Niesters, M., Dahan, A., Kest, B., Zacny, J., Stijnen, T., Aarts, L., et al. (2010). Do sex differences exist in opioid analgesia? A systematic review and metaanalysis of human experimental and clinical studies. Pain 151, 61-68. doi: 10.1016/j.pain.2010.06.012

Nuccio, R. P., Barnes, K. A., Carter, J. M., and Baker, L. B. (2017). Fluid balance in team sport athletes and the effect of hypohydration on cognitive, technical, and physical performance. Sports Med. 47, 1951-1982.

Ogino, Y., Kakeda, T., Nakamura, K., and Saito, S. (2014). Dehydration enhances pain-evoked activation in the human brain compared with rehydration. Anesth. Analg. 118, 1317-1325. doi: 10.1213/ANE.0b013e3182a9b028

Øian, P., Tollan, A., Fadnes, H. O., Noddeland, H., and Maltau, J. M. (1987). Transcapillary fluid dynamics during the menstrual cycle. Am. J. Obstet. Gynecol. 156, 952-955.

Okifuji, A., and Turk, D. C. (2006). Sex hormones and pain in regularly menstruating women with fibromyalgia syndrome. J. Pain 7, 851-859. doi: 10.1016/j.jpain.2006.04.005

Palit, S., Bartley, E. J., Kuhn, B. L., Kerr, K. L., DelVentura, J. L., Terry, E. L., et al. (2016). Endogenous inhibition of pain and spinal nociception in women with premenstrual dysphoric disorder. J. Pain Res. 9, 57-66. doi: 10.2147/JPR.S97109

Paller, C. J., Campbell, C. M., Edwards, R. R., and Dobs, A. S. (2009). Sex-based differences in pain perception and treatment. Pain Med. 10, 289-299. doi: 10.1111/j.1526-4637.2008.00558.x

Parker, J., Heinking, K. P., and Kappler, R. E. (2012). Efficacy of osteopathic manipulative treatment for low back pain in euhydrated and hypohydrated conditions: a randomized crossover trial. J. Am. Osteopath. Assoc. 112, 276-284.

Payne, L. A., Seidman, L. C., Sim, M.-S., Rapkin, A. J., Naliboff, B. D., and Zeltzer, L. K. (2019). Experimental evaluation of central pain processes in young women with primary dysmenorrhea. Pain 160, 1421-1430. doi: 10.1097/j.pain. 0000000000001516

Pfleeger, M., Straneva, P. A., Fillingim, R. B., Maixner, W., and Girdler, S. S. (1997). Menstrual cycle, blood pressure and ischemic pain sensitivity in women: a preliminary investigation. Int. J. Psychophysiol. 27, 161-166.

Pisanu, C., Franconi, F., Gessa, G. L., Mameli, S., Pisanu, G. M., Campesi, I., et al. (2019). Sex differences in the response to opioids for pain relief: a systematic review and meta-analysis. Pharmacol. Res. 148:104447. doi: 10.1016/j.phrs.2019. 104447

Pogatzki-Zahn, E. M., Mengersen, C., Englbrecht, J. S., Klein, T., Magerl, W., and Zahn, P. K. (2019). Progesterone relates to enhanced incisional acute pain and pinprick hyperalgesia in the luteal phase of female volunteers. Pain 160, 1781-1793.

Popescu, A., LeResche, L., Truelove, E. L., and Drangsholt, M. T. (2010). Gender differences in pain modulation by diffuse noxious inhibitory controls: a systematic review. Pain 150, 309-318. doi: 10.1016/j.pain.2010.05.013

Pross, N., Demazières, A., Girard, N., Barnouin, R., Santoro, F., Chevillotte, E., et al. (2013). Influence of progressive fluid restriction on mood and physiological markers of dehydration in women. Br. J. Nutr. 109, 313-321. doi: 10.1017/ S0007114512001080

Rainville, P., Feine, J. S., Bushnell, M. C., and Duncan, G. H. (1992). A psychophysical comparison of sensory and affective responses to four 
modalities of experimental pain. Somatosens. Mot. Res. 9, 265-277. doi: 10.3109/ 08990229209144776

Rezaii, T., and Ernberg, M. (2010). Influence of oral contraceptives on endogenous pain control in healthy women. Exp. Brain Res. 203, 329-338. doi: 10.1007/ s00221-010-2246-y

Rezaii, T., Hirschberg, A. L., Carlström, K., and Ernberg, M. (2012). The influence of menstrual phases on pain modulation in healthy women. J. Pain 13, 646-655. doi: 10.1016/j.jpain.2012.04.002

Rhudy, J. L., and Bartley, E. J. (2010). The effect of the menstrual cycle on affective modulation of pain and nociception in healthy women. Pain 149, 365-372. doi: $10.1016 /$ j.pain.2010.02.041

Rhudy, J. L., Bartley, E. J., Palit, S., Kerr, K. L., Kuhn, B. L., Martin, S. L., et al. (2013). Do sex hormones influence emotional modulation of pain and nociception in healthy women? Biol. Psychol. 94, 534-544. doi: 10.1016/j.biopsycho.2013.10. 003

Riley, J. L. III, Robinson, M. E., Wise, E. A., Myers, C. D., and Fillingim, R. B. (1998). Sex differences in the perception of noxious experimental stimuli: a meta-analysis. Pain 74, 181-187.

Riley, J. L. III, Robinson, M. E., Wise, E. A., and Price, D. D. (1999). A meta-analytic review of pain perception across the menstrual cycle. Pain 81, 225-235.

Sherman, J. J., and LeResche, L. (2006). Does experimental pain response vary across the menstrual cycle? A methodological review. Am. J. Physiol. Regul. Integr. Comp. Physiol. 291, R245-R256. doi: 10.1152/ajpregu.00920.2005

Sherman, J. J., LeResche, L., Mancl, L. A., Huggins, K., Sage, J. C., and Dworkin, S. F. (2005). Cyclic effects on experimental pain response in women with temporomandibular disorders. J. Orofac. Pain 19, 133-143.

Souza, M. J. D., Maresh, C. M., Maguire, M. S., Kraemer, W. J., Flora-Ginter, G., and Goetz, K. L. (1989). Menstrual status and plasma vasopressin, renin activity, and aldosterone exercise responses. J. Appl. Physiol. 67, 736-743. doi: 10.1152/jappl.1989.67.2.736

Spruce, B. A., Baylis, P. H., Burd, J., and Watson, M. J. (1985). Variation in osmoregulation of arginine vasopressin during the human menstrual cycle. Clin. Endocrinol. 22, 37-42. doi: 10.1111/j.1365-2265.1985.tb01062.x

Stachenfeld, N. S. (2008). Sex hormone effects on body fluid regulation. Exerc. Sport Sci. Rev. 36, 152-159. doi: 10.1097/JES.0b013e31817be928

Stachenfeld, N. S., DiPietro, L., Kokoszka, C. A., Silva, C., Keefe, D. L., and Nadel, E. R. (1999a). Physiological variability of fluid-regulation hormones in young women. J. Appl. Physiol. 86, 1092-1096. doi: 10.1152/jappl.1999.86.3. 1092

Stachenfeld, N. S., Silva, C., Keefe, D. L., Kokoszka, C. A., and Nadel, E. R. (1999b). Effects of oral contraceptives on body fluid regulation. J. Appl. Physiol. 87, 1016-1025. doi: 10.1152/jappl.1999.87.3.1016

Stachenfeld, N. S., and Keefe, D. L. (2002). Estrogen effects on osmotic regulation of AVP and fluid balance. Am. J. Physiol. Endocrinol. Metab. 283, E711-E721. doi: 10.1152/ajpendo.00192.2002

Stachenfeld, N. S., Splenser, A. E., Calzone, W. L., Taylor, M. P., and Keefe, D. L. (2001). Selected contribution: sex differences in osmotic regulation of AVP and renal sodium handling. J. Appl. Physiol. 91, 1893-1901. doi: 10.1152/jappl.2001. 91.4.1893

Stachoń, A. J. (2016). Menstrual changes in body composition of female athletes. Coll. Antropol. 40, 111-122.

Stephenson, L. A., and Kolka, M. A. (1988). Plasma volume during heat stress and exercise in women. Eur. J. Appl. Physiol. Occup. Physiol. 57, 373-381. doi: $10.1007 / \mathrm{BF} 00417979$

Stookey, J. D. (2005). High prevalence of plasma hypertonicity among communitydwelling older adults: results from NHANES III. J. Am. Diet. Assoc. 105, 1231-1239. doi: 10.1016/j.jada.2005.05.003

Świeboda, P., Filip, R., Prystupa, A., and Drozd, M. (2013). Assessment of pain: types, mechanisms and treatment. Ann. Agric. Environ. Med. 20, 2-7.
Szinnai, G., Schachinger, H., Arnaud, M. J., Linder, L., and Keller, U. (2005). Effect of water deprivation on cognitive-motor performance in healthy men and women. Am. J. Physiol. Regul. Integr. Comp. Physiol. 289, R275-R280. doi: 10.1152/ajpregu.00501.2004

Teepker, M., Kunz, M., Peters, M., Kundermann, B., Schepelmann, K., and Lautenbacher, S. (2014). Endogenous pain inhibition during menstrual cycle in migraine. Eur. J. Pain 18, 989-998. doi: 10.1002/j.1532-2149.2013.00444.x

Teepker, M., Peters, M., Kundermann, B., Vedder, H., Schepelmann, K., and Lautenbacher, S. (2011). The effects of oral contraceptives on detection and pain thresholds as well as headache intensity during menstrual cycle in migraine. Headache 51, 92-104. doi: 10.1111/j.1526-4610.2010.01775.x

Tomazo-Ravnik, T., and Jakopiè, V. (2006). Changes in total body water and body fat in young women in the course of menstrual cycle. Int. J. Anthropol. 21, $55-60$.

Tousignant-Laflamme, Y., and Marchand, S. (2009). Excitatory and inhibitory pain mechanisms during the menstrual cycle in healthy women. Pain 146, 47-55. doi: 10.1016/j.pain.2009.06.018

Treede, R.-D., Rief, W., Barke, A., Aziz, Q., Bennett, M. I., Benoliel, R., et al. (2015). A classification of chronic pain for ICD-11. Pain 156, 1003-1007. doi: 10.1097/j.pain.0000000000000160

Turk, D. C., Wilson, H. D., and Cahana, A. (2011). Treatment of chronic noncancer pain. Lancet 377, 2226-2235.

Unruh, A. M. (1996). Gender variations in clinical pain experience. Pain 65, $123-167$.

Vignolo, V., Vedolin, G. M., de Araujo, C. D. R. P., and Rodrigues Conti, P. C. (2008). Influence of the menstrual cycle on the pressure pain threshold of masticatory muscles in patients with masticatory myofascial pain. Oral surg. Oral Med. Oral Pathol. Oral Radiol. Endod. 105, 308-315. doi: 10.1016/j.tripleo. 2007.08.044

Vokes, T. J., Weiss, N. M., Schreiber, J., Gaskill, M. B., and Robertson, G. L. (1988). Osmoregulation of thirst and vasopressin during normal menstrual cycle. Am. J. Physiol. Regul. Integr. Comp. Physiol. 254, R641-R647. doi: 10.1152/ajpregu. 1988.254.4.R641

Volpe, S. L., Poule, K. A., and Bland, E. G. (2009). Estimation of prepractice hydration status of National Collegiate Athletic Association Division I athletes. J. Athl. Train. 44, 624-629. doi: 10.4085/1062-6050-44.6.624

Willoughby, S. G., Hailey, B. J., Mulkana, S., and Rowe, J. (2002). The effect of laboratory-induced depressed mood state on responses to pain. Behav. Med. 28, 23-31. doi: 10.1080/08964280209596395

Wilson, H., Carvalho, B., Granot, M., and Landau, R. (2013). Temporal stability of conditioned pain modulation in healthy women over four menstrual cycles at the follicular and luteal phases. Pain 154, 2633-2638. doi: 10.1016/j.pain.2013. 06.038

Yarnitsky, D., Arendt-Nielsen, L., Bouhassira, D., Edwards, R. R., Fillingim, R. B., Granot, M., et al. (2010). Recommendations on terminology and practice of psychophysical DNIC testing. Eur. J. Pain 14:339. doi: 10.1016/j.ejpain.2010.02. 004

Conflict of Interest: The authors declare that the research was conducted in the absence of any commercial or financial relationships that could be construed as a potential conflict of interest.

Copyright (c) 2020 Tan, Philipp, Hill, Che Muhamed and Mündel. This is an openaccess article distributed under the terms of the Creative Commons Attribution License (CC BY). The use, distribution or reproduction in other forums is permitted, provided the original author(s) and the copyright owner(s) are credited and that the original publication in this journal is cited, in accordance with accepted academic practice. No use, distribution or reproduction is permitted which does not comply with these terms. 